\title{
MEMOGRAFIAS DE FÉ
}

Denise Maria Botelho ${ }^{1}$

DOI 10.26512/revistacalundu.v4i1.32230

\begin{abstract}
Resumo
Este é um texto que articula um material autobiográfico, situando minha posição como mulher negra, ativista antirracista e antissexista e, sobretudo, o percurso de minha formação como ialorixá do candomblé. Busco aqui refletir sobre os modos como a trajetória de vida, retomada pela memória, atribui sentidos, inspira lutas, inclusive as nossas mesmas, constrói agendas e posiciona nossas vidas em relação ao gesto da fé, que, no candomblé e em outras religiões de matrizes afro-indígenas, é sempre acompanhado de ações em comunidade. Em função do apelo à memória, este trabalho não trará aportes bibliográficos, mas aqueles que, encarnados na oralidade, trazem elementos da história vivida que penso serem suficientes para articular esse vínculo entre trajetória, luta política e religiosidade. Não se trata de negar a pesquisa, pois eu mesma sou uma pesquisadora, mas em priorizar, nesse relato, o que minha própria história me legou.
\end{abstract}

Palavras-chave: Candomblé. Ativismo. Educação para paz. Mulheres de Axé. Memória.

\section{MEMOGRAFIAS DE FÉ}

\section{Resumen}

Esto texto articula material autobiográfico, situando mi posición como mujer negra, activista antirracista y antisexista y, sobre todo, el curso de mi formación como ialorixá del candomblé. Busco aquí reflexionar sobre las formas en que la trayectoria de vida, tomada por la memoria, atribuye significados, inspira luchas, incluida la nuestra, construye agendas y posiciona nuestras vidas en relación con el gesto de la fe, que, en Candomblé y otras religiones de matrices afro-indígenas, siempre va acompañado de acciones comunitarias. Debido al atractivo de la memoria, este trabajo no aportará contribuciones bibliográficas, sino aquellas que, encarnadas en la oralidad, aporten elementos de la historia vivida que creo que son suficientes para articular este vínculo entre trayectoria, lucha política y religiosidad. No se trata de negar la investigación, ya que yo misma soy una investigadora, sino de priorizar, en este contexto, lo que mi propia historia me ha dejado.

\footnotetext{
${ }^{1}$ Professora Associada do Departamento de Educação da Universidade Federal Rural de Pernambuco. Professora Orientadora do Programa de Pós-Graduacao em Educação, Culturas e Identidades (UFRPE/Fundação Joaquim Nabuco). Líder do Grupo de Pesquisa em Educação, Raça, Gênero e Sexualidades Audre Lorde. E-mail: denise.botelho@ufrpe.br
} 
Palabras clave: Candomblé. Educación para la paz. Activismo. Mujeres de Axé. Memoria.

\begin{abstract}
Exu, Senhor da Comunicação, permita que as minhas palavras sejam construtivas. Laroye!!!! Ogun, ferreiro celestial, mojuba. Oyá, espelho de um feminino autônomo, epahey! Osun que refresca meu Ori e me concedeu o sacerdócio, ore ye, ye!
\end{abstract}

Nascida na cidade de São Paulo, cursei toda a Educação Básica em escolas públicas, ao término do $2^{\circ}$ grau, nomenclatura da época para o ensino médio atual, tentei ingressar nas Forças Armadas: percebia uma possibilidade de ascensão social pelos meus méritos e não pela quantidade de melanina da minha pele. Apesar de pouca idade, mesmo sem teoria, já sabia o que era racismo desde a experiência dolorosa com a professora Terezinha ( $3^{\mathrm{a}}$ série/ano) quando ela me disse "que eu não servia nem para varrer a sala de aula".

A escola técnica, também, não me ajudou: fiz o curso técnico em secretariado, e quando os classificados anunciavam vagas com boa aparência, já sabia que não teria êxito na busca profissional. Não consegui ingressar nas Forças Armadas, por um problema na coluna, então retomei o projeto de cursar uma faculdade. Cumprindo "a determinação social”, a maioria dos(as) jovens que cursaram educação básica pública, não conseguiam passar no chamado ensino superior; não foi diferente comigo, consegui ingressar em uma faculdade privada, para o noturno; afinal era preciso trabalhar de dia para pagar o curso da noite.

Na universidade pública a lógica inverte-se e os filhos do grupo hegemônico, como acessaram ótima formação básica, na maioria das vezes acessam as universidades públicas, que são consideradas de melhor qualidade na realidade brasileira. Consigo romper o círculo vicioso apenas na pós-graduação, depois de onze anos trabalhando na Universidade de São Paulo e convivendo com muitos exemplos positivos.

Tentei ingressar no mestrado e, depois de três tentativas, realizei meu sonho, mas tendo, antes, que cumprir dois semestres no curso de Ciências Sociais, para atender uma avaliação do meu professor orientador, que seria necessário balizar meus conhecimentos, uma vez que eu era Pedagoga oriunda de uma faculdade particular e ele sociólogo; foi uma experiência interessante apesar de atrasar meu trajeto acadêmico em 
um ano, mas foi possível realizar o mestrado com um posicionamento diferenciado da maioria de meus pares: o que faltou-me na formação inicial, em relação a posicionamento crítico, um ano de Faculdade de Filosofia, Letras e Ciências Humanas (FFLCH/USP) deu-me de bons subsídios.

A formação em um mestrado interdisciplinar - Programa de Integração da América Latina PROLAM/USP - foi um outro diferencial em meu trajeto intelectual, no PROLAM eu cursei disciplinas na Faculdade de Educação, na Arquitetura, na Economia, no Direito. Considero que olhar os fenômenos sociais de forma complexa auxiliam o(a) pesquisador(a) em uma melhor compreensão dos problemas educacionais e outros que afligem o Brasil e agravam as desigualdades socioeconômicas e as étnicoraciais.

Como mulher negra, a temática da educação das relações étnico-raciais aparece, de forma consciente, apenas no mestrado, cursando a disciplina a "Identidade do docente" sob a responsabilidade da professora Roseli Fischmann. A própria professora Roseli estimulou-me em desenvolver um projeto com temática central sobre educação e a população afro-brasileira, afinal, eram poucos negros(as) na USP e deveríamos protagonizar pesquisas relacionadas à nossa cultura, a nossa história, a nossa religião, enfim, ter voz por nós mesmos(as).

Confesso que foi dolorido. Eu não me pensava como uma mulher negra, naquela época, passei por uma crise existencial e fiz a transição de "mulata" para a mulher negra que sou hoje, a partir da provocação acadêmica e da pesquisa que realizei sobre racismo em São Paulo e Havana.

De forma geral, quem se preocupava com o racismo educacional eram professores(as) negros(as) que haviam sentido o racismo na própria pele e gostariam de modificar a realidade educacional. Apenas algumas poucas pessoas não-negras aliadas apoiavam ou desenvolviam atividades de educação das relações étnico-raciais.

O pior é pensar que, passada mais de uma década, a realidade obteve pequenas transformações para o tamanho da necessidade de alterações sócio-raciais. Não havendo muito mais o que refletir sobre o sistema educacional brasileiro, decidi realizar a pesquisa do doutorado em um terreiro de candomblé que, na minha compreensão, produzia processos educativos a partir de referências de inclusão, de coletividade e de respeito à natureza. De fato, a pesquisa indicou que os terreiros podem e devem ser locus de educação étnico-racial por preservarem e perpetuarem a cultura africana e afro- 
brasileira. Afinal, o Artigo 26-A da LDB preconiza o estudo da história e da cultura afro-brasileira e indígena (Leis 10.639/2003 e 11.645/2008).

Muitas aprendizagens me foram reveladas entre os resultados da pesquisa. O que mais me chamou a atenção foi o papel social das mulheres de axé. São elas que, na maioria das vezes, preservam e socializam os conhecimentos ancestrais africanos. Encantei-me pelas mulheres de candomblé a tal ponto que, em 2018, desenvolvi um projeto de pesquisa de pós-doutoramento, junto à Universidade Federal da Paraíba, intitulado "Mulheres de axé: tradição e modernidade". No $15^{\circ}$ Festival Cara e Cultura Negra, em Brasília, apresentei alguns frutos de minhas reflexões sobre a pesquisa com mulheres de axé. As mulheres de axé sofrem pela questão de gênero, e, quando negras, pelo racismo; e agora, mais do que nunca, em função do crescente racismo religioso que se apresenta na sociedade brasileira de forma constante e violenta e por estas interseccionalidades, merecem ser protagonistas das suas próprias histórias e das religiões afro-indígenas.

Antes disso, eu já havia ingressado no magistério público desde 2006, na Universidade de Brasília, permanecendo lá até 2011 quando consegui uma redistribuição para a Universidade Federal Rural de Pernambuco, localizada na cidade de Recife. As pessoas acolheram-me afetuosamente e a diversidade cultural, com forte viés negro, foi uma das questões que me encantou. Penso viver aqui nestas terras até retornar à massa primordial. Na atualidade, sou Professora Associada do Departamento de Educação (DED) da Universidade Federal Rural de Pernambuco (UFRPE). Docente Orientadora do Programa de Pós-Graduação em Educação, Culturas e Identidades (PPGECI-UFRPE/FUNDAJ) nas linhas de pesquisas 1- Movimentos Sociais, Práticas Educativo-Culturais e Identidades e 3 - Políticas, Programas e Gestão de Processos Educacionais e Culturais. Líder do Grupo de Estudos e Pesquisas em Educação, Raça, Gênero e Sexualidades Audre Lorde (GEPERGES Audre Lorde). Membro do Coletivo de Acadêmicas Negras Luiza Bairros (CAN Luiza Bairros). Desenvolvo atividades de ensino, pesquisa e extensão em educação e relações raciais com viés em gênero e sexualidades; religiões de matrizes africanas e afro-indígenas.

Esta minha apresentação de uma trajetória profissional acadêmica não está dissociada de um aspecto que até agora não falei, minha pertença a uma das religiões de matrizes africanas, o candomblé. A mulher negra que sou foi forjada pelo ferro de Ogum, pelos ventos de Oyá e embalada pelos braços seguros e acolhedores de Oxum. E esta dimensão também precisa ser localizada em minha trajetória. Eu não apenas sou 
uma professora universitária de uma universidade pública federal, mas sou também uma Ialorixá.

Recordo-me que, em minha primeira infância, meu pai era umbandista e minha mãe tinha necessidade de desenvolvimento espiritual, mas tinha muito medo, herança do seu catolicismo mineiro. Eu, em compensação, ficava alucinada quando via meu pai incorporar algum espírito. Havia um fascínio em manter contato com o além. Eu gostava muito de uma entidade que meu pai recebia, o Marujo Aristides, uma figura bastante cômica, digamos assim.

E por essas obras do destino, como eu segui no caminho da espiritualidade de meu pai, hoje tenho comigo essa mesma entidade que quando "vem à terra" faz as pessoas sorrirem. E eu acho que é por isso que eu gostava dessa entidade, porque hoje há tantos motivos para gente chorar, que fazer sorrir é uma arte. E quando o sorriso aparece no rosto, espanta muitas negatividades. Então, eu tenho essa recordação - acho que eu tinha uns seis anos de idade quando isso acontecia, mas, infelizmente, meu pai abandonou o caminho da espiritualidade afro-brasileira.

Eu fiquei sem ter contato com essa religião até que quando eu completei 13 anos, após o falecimento precoce de minha mãe, quando uma vizinha me levou a um terreiro de umbanda. E posso declarar, desde já, que foi esse terreiro de umbanda que foi o meu referencial, porque, na época, meu pai tinha problemas com o alcoolismo e não conseguia ter um comportamento de pai. Houve uma inversão na família e acabei assumindo as responsabilidades da casa e sobre meu irmão caçula.

A umbanda, com as suas entidades - em especial com a baiana Açucena - que foi meu organizador psíquico, porque era ela que me orientava, era ela que me puxava a orelha, era ela que me dizia o quão importante era seguir o caminho da religiosidade. Eu fiquei nesse terreiro de mãe Dilce até completar 20 anos. Mas, infelizmente, ela mudouse para o interior e não tive mais condições de acompanhar aquele grupo do qual sinto muita falta, porque eu praticava uma umbanda, nesse terreiro, que havia uma orientação de que os guias deveriam trabalhar em benefício e não em malefício das pessoas.

Quando esse terreiro foi embora, procurei outros terreiros, mas não me adaptei porque havia a prática do malefício. E o que aprendi nos sete anos que fiquei na casa de Mãe Dilce foi o exercício da caridade. Então, não tinha condições de aderir a essas casas. Acabei tendo um afastamento. Mas, para usar as aprendizagens que tive nesse primeiro terreiro, fui para a Igreja Messiânica Mundial do Brasil, que é uma igreja de origem oriental, o que significa dizer que o modus operandi da cultura era 
completamente diferente da que eu experimentei antes. Por um bom período, fiquei nesta religião. Tenho gratidão porque eu aprendi, nesse exercício de fé, a servir, a fortalecer a minha procura de oferecer bem-estar às pessoas, pela prática do johrei (oração ativa, por intermédio de imposição das mãos), aprendi ikebana (arranjos florais) que me equilibrou muito emocionalmente.

No culto aos antepassados, a gente tinha condições de louvar todo nosso tronco ancestral e tenho impressão de que foi isso que me fez ficar um bom tempo na Igreja Messiânica. Sou muito agradecida, mas preciso abrir um parêntese: o princípio da religiosidade messiânica é a lei do altruísmo; entretanto, você faz para o outro antes de fazer para você mesma. Nesse momento da vida, com a experiência que eu tenho hoje, com as reflexões que faço, penso que é necessário que nós estejamos nos cuidando primeiro para depois poder cuidar dos demais, porque, efetivamente, estarei mais forte, estarei mais equilibrada para ajudar. Não pode ser um altruísmo que deixe margem para uma posição autodestrutiva.

Acho que o amor altruísta é importante, ele deve ser praticado; mas há uma primeira etapa: o autocuidado. E isto é algo que hoje eu prezo muito, porque compreendo que se a gente aprende a cuidar de si, aprende a cuidar melhor do mundo. Já na prática do candomblé que entendi a necessidade do autocuidado, quando realizei o meu primeiro borí (ritual de reequilíbrio espiritual e emocional) onde o nosso orí (cabeça) tem sua força vital reavivada.

Paralelamente, ingressei no Núcleo de Estudos Interdisciplinares sobre o Negro Brasileiro (NEINB), em 1996, sob a coordenação da professora doutora Ronilda Ribeiro. Com o ingresso no núcleo, fui ampliando a minha percepção das relações étnico-raciais no país e, principalmente, fortalecendo a minha identidade de mulher negra que, até então, não era existente. Melhor dizendo, porque eu não tive uma base familiar para me preparar para perceber o racismo constante em meu cotidiano, o que se modificou com minha ida para o núcleo.

Foi em uma das atividades do núcleo que conheci um terreiro de candomblé que, até então, eu nunca tinha visitado, até porque em São Paulo, pelo menos entre os contatos que eu tinha, havia uma certa resistência dos umbandistas em relação ao candomblé. No candomblé há a sacralização dos animais para a alimentação, e como as pessoas que não estão dentro da religião não tinham compreensão do significado disso, havia uma certa resistência. 
Ingenuamente, achei que estava indo na condição de uma pesquisadora conhecer a religião do candomblé. Eu me recordo que a primeira festividade que eu fui era um Olubajé, a comemoração do rei Omolu. Eu fiquei maravilhada, porque eu já tinha a experiência anterior da Umbanda, que é muito mais simples, que não tem, digamos, algumas particularidades nas cantigas, vestimentas e danças dos orixás.

Foi um encantamento e fiquei maravilhada nessa festa. Depois, fiquei bastante sensibilizada, acho que fui buscar acender a chama da minha fé diaspórica. Isso aconteceu em agosto de 1996. Em dezembro do mesmo ano, fui numa festa de Oxum que era a divindade da ialorixá da casa. Nesse dia, passei mal - ou, melhor dizendo, passei bem - e isso foi uma manifestação de Ogum, que desde a Umbanda já era o orixá que rege minha vida.

Fiquei muito assustada porque, na época, eu ainda era vinculada à Igreja Messiânica, inclusive com cargos de liderança jovem. Já tinha sido professora no seminário da Igreja, então aquilo para mim sim foi bastante confuso, mas, ao mesmo tempo, de uma intensidade que, por mais que a minha racionalidade dissesse não, o meu chamado ancestral foi muito maior. Em março de 1997, fiz um borí para começar a frequentar e conhecer o lugar, porque eu não conhecia ninguém na casa, não tinha nenhuma relação e, de fato, eu não tive esse tempo de abiã (membro frequentador não iniciado), que considero um tempo precioso, pois em julho do mesmo ano fui iniciada.

$\mathrm{O}$ meu retorno à religião dos meus ancestrais, após ter passado pela realidade da igreja messiânica Mundial do Brasil, na qual a lógica missionária era o desenvolvimento do amor altruísta, e também pela confederação brasileira espírita. Ambas as experiências têm seus méritos: de todas as aprendizagens temos algo a colher. Confesso que muito da minha prática hoje, na liderança de um terreiro, tem a ver com outros ensinamentos aprendidos nesses espaços e também com algumas dores, porque a prática do altruísmo, acredito, é válida a partir do momento que você está bem orientado(a), porque você não pode fazer para o outro aquilo que não está bem em você. Reconheço, mas penso que na nossa religião, a cerimônia do borí é algo muito interessante, porque antes de você cuidar do outro é preciso despertar o que existe dentro de cada um de nós. E, assim, nos reencontramos com nossa essência, com aquilo que nos colocamos como missão, antes de virmos para a terra. Você se equilibra, para poder depois cuidar dos outros, com oferendas, cantigas e muitos votos de alegria, paz, sucesso, prosperidade, saúde e tudo aquilo que fará a pessoa se orientar. 
Essa é uma observação que eu faço porque tenho a impressão que, no candomblé, precisamos, ainda, ampliar a valorização do orí - essa cabeça interior, sede de nossa individualidade e contato com nossa ancestralidade - enquanto portador da nossa missão primordial, enquanto aquele que guarda o nosso segredo divino. Em alguns cultos africanos e em algumas tradições do candomblé, o orí é uma divindade, tem um assentamento, o Ibá Orí. Penso que é algo para nós refletirmos porque essa divindade é a nossa essência e quando estamos bem com a nossa essência, tudo tende a fluir bem.

Depois de quase 23 anos de iniciada para o orixá, percebo que eu bebi em várias fontes. No começo achava isso ruim porque eu queria ter um único porto seguro e seguir aquela tradição, mas cada um tem o seu percurso de aprendizagens. Posso dizer que tive, no mínimo, cinco mulheres de Oxum que me cuidaram. Mãe Vanda, foi a pessoa que me iniciou, e a quem sou eternamente grata, porque foi ela quem trouxe Ogum para mais perto ainda de meu mundo. Após esse período, tive contato com Iyá Suru de Oxum, quando me aproximei da religião tradicional iorubá e compus esse grupo sob a liderança dela, no qual aprendi também determinadas formas de culto que não são comuns no Brasil. E quando a necessidade aparece, me utilizo dessas forças. Depois disso eu me mudei para Brasília, onde tive a grata satisfação de encontrar mãe Railda de Oxum. Quando eu a conheci, estava em uma época que eu não queria mais tomar obrigação com nenhuma ialorixá de Oxum. Mas essa decisão não era minha. Sempre baseei meu caminho na escolha feita pelo Orixá.

Como exemplo, eu já tinha decidido que eu completaria meu ciclo de sete anos com o babalorixá Aurélio de Inle, que é uma pessoa por quem tenho um grande carinho. Mas na primeira visita à casa de Mãe Railda, Ogum se manifestou e, a partir dali, compreendi que ele queria que ela fechasse o meu ciclo iniciático. E assim foi. Eu sou agradecidíssima porque Mãe Railda deu a maioridade a mim na religião, o que me fez mais forte para seguir o caminho dos orixás. Sou grata também a minha mãe criadeira, mãe Maria de Oyá, do Ilê Axé Opô Afonjá do Rio de Janeiro. Ambas são mulheres que dedicaram a vida inteira para a religião e que, até hoje, por mais intempéries que tenham ocorrido, elas não abrem mão desse lugar e de suas funções.

Depois de Brasília, me mudo para Pernambuco, onde começo a atender algumas pessoas a partir de minha espiritualidade na Umbanda. E, a partir desse início em Recife, com a umbanda, foram aparecendo episódios em que era necessário trazer também os saberes e práticas do Candomblé. Nem todos estão na Umbanda e nem todos 
estão com o candomblé e alguns, como no meu caso, estão ligados com as duas distintas religiões, uma vez que uma é uma herança familiar do meu pai, a Umbanda, e a outra era meu compromisso que meu orí assumiu, o Candomblé.

Quando me mudei para Pernambuco, ainda ficava indo e voltando para Brasília porque meus orixás ainda haviam ficado lá. Eu tinha uma prática de tentar, o máximo possível, participar das atividades sociais na casa de mãe Railda. E com o tempo isso foi ficando mais difícil. E, então houve o episódio que minha mãe Railda cansou. Cansou não dos orixás, mas das ingratidões e vendeu a chácara onde ficava o terreiro dela.

Quando isso aconteceu, ela pediu para que os filhos pegassem os orixás e eu fui para Brasília. Em um primeiro momento trouxe o Exu Tiriri e Ogum para minha casa e separei um lugar, um espaço que fosse exclusivo de cada um. Logo em seguida foi preciso trazer todos os meus outros assentamentos de orixás, porque meu pai Ogum tinha vindo e eles ficaram para trás e não ficaram nada felizes. Então, em menos de três meses eu tinha quase todos na minha casa. Só faltava a família Iji, isso é, a família da palha.

E, nesse período, foram também aparecendo mais pessoas que tinham sido chamadas pelo candomblé e não apenas a umbanda. E aí eu fui tentando intermediar essas duas religiões nas quais fui iniciada. Até que foi necessário assumir um processo de liderança religiosa, com um porém: eu não era apenas uma liderança religiosa, era também professora universitária. São duas funções que ocupam espaços muito significativos na minha vida.

Trilhar o caminho da academia, eu tenho certeza, que foi um movimento do orixá, e que foi abençoado pelo meu orí porque, como mulher negra, todos nós sabemos que estou na base da pirâmide social, mas que venho, orgulhosamente, de uma tradição de mulheres empregadas domésticas e, hoje, ser professora universitária só foi possível quando renasci na religião do candomblé Ketu e que eu pude descobrir a minha verdade, as minhas possibilidades e trabalho desde sempre com relações étnico-raciais e, nos últimos tempos, mais próxima da reflexão sobre as mulheres de axé.

Então, ora a religião me leva para academia e ora a academia me traz para a religião. Isso significa dizer que, muito provavelmente, a forma de lidar com os(as) filhos(as) tenha a minha especificidade, já que a maioria das nossas mais velhas, pelo processo racista e sexista da sociedade, não tiveram condições de acessar o mundo acadêmico, com raríssimas exceções. 
Embora a academia não pudesse ter dado a elas a sabedoria - sabedoria que a gente aprende no chão do terreiro - então eu vivo essa lógica da teoria na academia e da prática no terreiro. Sou de ideologia socialista, mas não o socialismo ocidental, sou na verdade uma socialista afro-indígena, porque foi essa formação que eu tive nos terreiros. Se na sociedade civil o socialismo é uma utopia, dentro das comunidades de terreiro, tenho visto isso acontecer.

Somos, consciente ou inconscientemente, levados a pensar no outro quando a gente está fazendo uma comida para um ebó, seja para um cliente ou para um amigo, a gente se reúne para fazer o ossé da casa, a gente agradece a permissão de estarmos todos ali reunidos, para que não aconteça nada de ruim, agradecendo o que aconteceu. São práticas que, com o desenvolvimento do capitalismo, foram ficando perdidas.

Para a gente ser mais humano: poder ser mais do que poder ter, as religiões de matrizes africanas resgatam isso. Obviamente que nós temos desejo também de ter. Vivemos nessa realidade partilhada com o mundo ocidental capitalista. Porém é ainda mais importante o caminho dos orixás. Precisamos dos orixás, mas os orixás também precisam de nós, para que haja a continuidade. Eles precisam de seus filhos e filhas, em uma simbiose, na qual ninguém é mais do que ninguém: todos nós somos importantes, necessários e necessárias.

Depois de minha vinda para o nordeste, eu realmente assumi a liderança de uma casa de candomblé com ajuda de vários mais velhos. Agradeço imensamente aos orixás que sempre colocaram pessoas no meu caminho, mesmo que fossem por um curto período de tempo, como no caso de Mãe Ana de Oxum, mas elas foram colocadas naquele momento para realizar o que era necessário. Algumas permaneceram na minha vida para sempre.

Hoje, tenho a grata satisfação de receber orientações de Mãe Lúcia Omidewá, que é uma pessoa bastante generosa na divisão dos conhecimentos sobre orixás. Eu sou jovem, em relação a muitas coisas que tenho que aprender pelo caminho, mas Iyá Lúcia tem muita paciência e não nega informações, como sua vida religiosa começou na infância com a Jurema Sagrada, com a Umbanda, depois pelos candomblés nagô, jeje e ketu. Em março de 2000, Mãe Stela de Oxóssi, plantaria o axé do terreiro e passaria a ser a ialorixá de mãe Lúcia. O conhecimento acumulado na sua trajetória e sua característica autodidata a faz uma expert das religiões afro-indígenas. Adupé Oxum, sempre no meu caminho! 
Registro minha gratidão por todas aquelas pessoas com as quais eu convivi e convivo e virei ainda conviver-nos candomblés das diversas nações porque são eles que renovam a minha esperança. São eles que me fazem acreditar que é possível viver a utopia da comunidade solidária, sustentável, de viés afro-indígena.

São os parentes indígenas que também me fortalecem com o que é necessário para preservarmos a natureza, porque ela é parte da nossa vida; o planeta é vivo. Nós que cultuamos orixá não podemos desrespeitar a natureza, poluir o mar, sujar as praias, esgotar a terra, poluir o ar. Essas práticas negativas devem ser banidas de nossa vida nas atividades cotidianas, para que todos nós possamos dar frutos como a natureza. Os frutos que eu espero dar são de pessoas que cultuem verdadeiramente orixá e não o seu ou sua dirigente religiosa, mas aquelas pessoas que têm fé nos orixás, nas entidades, nos mestres, nos encantados, e que acreditam que é possível viver na modernidade, porém baseadas em valores de uma tradição ancestral africana.

Viver a realidade desta utopia das comunidades de terreiro, que estão em confronto direto com a lógica do capitalismo, na qual o mercado tem uma importância soberana, acima de qualquer ser, faz com que nós abracemos várias frentes de lutas.

Enquanto mulher negra, lésbica eu já teria como condição de vida o engajamento nos movimentos sociais, seja no movimento de mulheres negras, seja no movimento LGBTTQI+, seja no movimento de mulheres de axé. A religião foi me dando uma consciência do lugar do feminino como extremamente importante.

No doutorado comecei a trabalhar com o candomblé na pesquisa, buscando alternativas de valorização da cultura negra, a partir do artigo 26A da LDB. Nessa perspectiva, vejo que há um lugar posto, em especial nos candomblés mais antigos, que são dirigidos por mulheres. Pegando o caso, na Casa Branca, onde tudo começou, até o presente temos lideranças femininas, e não é diferente no Gantois, e nem na minha linhagem do Axé Opô Afonjá, tanto no Rio de Janeiro, como em Salvador.

O candomblé me mostrou uma força que, até então, eu desconhecia, inclusive nesta perspectiva política. Depois de minha iniciação, eu atuei na ONG Geledés, que completou minha formação de ativista negra. Mas o que me deu força mesmo é o que eu encontrei no terreiro. Por exemplo, quando ouço um itã de Oyá e vejo a imagem da mulher guerreira, uma mulher que pode ter como simbologia uma borboleta e uma búfala, penso que também posso alcançar a possibilidade de saber a hora da búfala e a hora da borboleta é um aprendizado sem igual. 
Ao mesmo tempo, o terreiro foi me abrindo os olhos para perceber como em nossa sociedade, fora do terreiro, sobretudo aqueles que tem princípios matrilineares, as coisas são muito diferentes. Os números da violência doméstica são assustadores. Entretanto, nas comunidades de terreiro, nós procuramos nos proteger uns aos outros, diferentemente do que ocorre nessa comunidade de fora dos terreiros, onde quando temos um casal brigando, coloca-se em prática o ditado de que "em briga de marido e mulher não se mete a colher”.

Já no terreiro, pensamos diferente. A comunidade é, também, responsável pela felicidade de seus membros. Então, se um casal não está bem, ele precisa ser equilibrado. E se, nesse processo de busca de equilíbrio, se não for possível superar o machismo que perpassa as relações, nós teremos que fortalecer essa mulher, para que ela possa ser protagonista de sua própria existência.

Não se trata de fazer as coisas por ela, pois se isso acontece, ela não ganhará sua própria autonomia. Então é necessário que se tenha a autonomia para dar condições para que, também, no caminho dos orixás, a gente possa se libertar das mazelas que existem na sociedade.

O candomblé é a religião que aceita o maior número de homossexuais. Isso é verdade, nós encontraremos gays, lésbicas e, mais atualmente, pessoas transexuais, dentro dos terreiros, o que não significa que o acolhimento destas pessoas seja o mesmo daquelas pessoas que se comportam conforme uma lógica heteronormativa, essa é uma questão que precisamos refletir.

$\mathrm{Na}$ minha casa isso toma outros rumos, pelo fato de eu ser lésbica, assumida, e nunca ter escondido isso. $\mathrm{E}$ nem por isso, me foi retirada a possibilidade da maternidade. Enquanto mulher lésbica tenho um desejo afetivo-sexual por mulheres. Entretanto, o desejo pela maternidade, que pode ser pensada desde uma lógica heteronormativa, sempre esteve presente em mim, desde minha infância. Eu que me preparei, para ter um ou dois filhos, hoje tenho muitos(as) filhos(as), tendo em consideração que sou uma Iyá e gero os(as) rebentos(as) que Ogun me concedeu.

Lidar com essas personalidades, em suas várias formas, com pessoas de níveis sociais diferenciados, nos coloca - a maioria das ialorixás -, na prática, em psicoterapeutas, economistas, conselheiras, junto de nossa função religiosa. Vamos dando conta destas várias frentes. E, nesse caso, não se trata de ser homem ou mulher, mas de haver uma mulher que é uma liderança, o que, por si só, nos permite estar em um outro lugar na vida. 
E este ensinamento eu levo para a minha prática de professora, formadora de professoras e professores, na qual tenho como perspectiva desmistificar os tabus em se falar de religião, em especial de religiões de matrizes africanas ou afro-indígenas, de falar sobre diversidade sexual e de identidade de gênero, para podermos ser pessoas mais solidárias. São aspectos que, desde a vivência com a diversidade nos terreiros pelos quais passei e, agora, no qual eu estou dirigente, me fazem ter uma postura de compreensão e acolhimento.

Acho que esta é a questão mais importante das religiões afro-indígenas, que é a situação do acolhimento. E isso fez muita diferença na minha vida e tento que faça diferença na vida das minhas filhas e dos meus filhos.

E espero que um dia possamos superar este racismo religioso, que tem feito como vítimas religiosos(as) afro-indígenas, tudo isso moldado nesse racismo que está enfronhado na sociedade brasileira, de modo que tudo aquilo que está relacionado com a cultura negra é negativado, desvalorizado, demonizado.

Um dia veremos que todos nós caminhamos para um bem em comum. Para um bem-viver. Os caminhos são diferentes, mas o objetivo é único. E para isso precisamos superar a ignorância, o desconhecimento que existem. As pessoas têm raiva, ódio, daquilo que elas nem conhecem. Elas têm raiva e ódio de uma projeção que é dada por outros, mas que não correspondem às nossas religiões que, apesar de algumas exceções, nos ensina a ser solidários, a cuidar da natureza e do próximo, a ter uma atitude de responsabilidade com os pares. Espero que as pessoas tenham a chance de conhecer o que realmente são as nossas religiões.

Desejo que vocês sempre vivam a alegria de meu Pai Ogun, que as suas atitudes não os façam encontrar com a ira de Ogun. Ogunhê!!!

Recebido em: 13/04/2020

Aceito em: 15/04/2020 